Original Research Article

\title{
Periodic evaluation of drug utilization in intensive coronary care unit patients in a tertiary care hospital
}

\author{
Sangeeta Nath Sharma ${ }^{1 *}$, Rajendra Holla ${ }^{1}$, Subramanyam K. ${ }^{2}$, Mangala Srinivas ${ }^{1}$
}

\begin{abstract}
${ }^{1}$ Department of Pharmacology,
${ }^{2}$ Department of Cardiology, K S

Hegde Medical Academy,

Mangalore, Karnataka, India

Received: 22 November 2017

Accepted: 28 December 2017

*Correspondence to:

Dr. Sangeeta Nath Sharma,

Email: sharmavidushi.7@

gmail.com
\end{abstract}

Copyright: (C) the author(s), publisher and licensee Medip Academy. This is an openaccess article distributed under the terms of the Creative Commons Attribution NonCommercial License, which permits unrestricted noncommercial use, distribution, and reproduction in any medium, provided the original work is properly cited.

\begin{abstract}
Background: A wide and gradual variation exists periodically in the patterns of pharmacotherapy among patients admitted with CVDs in CCU. Periodic evaluation of drug utilization in the CCU is necessary for optimization of health care system, proper use of resources and making prescription policy.

Methods: It was retrospective and prospective study. Study was carried out at Tertiary care hospital in Mangalore. Retrospective study period was from 1/07/2010 till 31/12/2010 and Prospective study duration was from 1/01/2016 till 30/06/2016. Patients from CCU were participants of this study.

Results: Data of total 278 patients were taken, out of which 138 patients from 2010 and 140 patients in 2016 were analyzed respectively and were compared among drug therapy for IHD - Nitrates, dual antiplatelet therapy (aspirin and clopidogrel), dyslipidemic drugs and beta blockers remain drug of choice in both retrospective and prospective study. But, anticoagulant (heparin/ LMWH) use increased in prospective studies. In Heart failure - nitrates, antiplatelet, dyslipidemic drugs followed by inotropes and diuretics was used in both study. Cardiomyopathy was managed with diuretics, ACEIs, and nitrates in both retrospective and prospective study.

Conclusions: In conclusion, predominance of male gender and poly-pharmacy were observed. However, it has identified areas to further rationalize and optimize patterns of polypharmacy and evidence based use of medications like beta blockers, anticoagulants/antiplatelet agents and antiarrythmisc. The results on the major determinants of cardiovascular drug use in CCU matched with the existing indications and cautions for use with each drug class.
\end{abstract}

Keywords: Arrhythmia, Cardiomyopathy, CCU, IHD, Polypharmacy

\section{INTRODUCTION}

Northern Europe and the United Kingdom took initiative in mid 1960 in the development of drug utilization research. ${ }^{1}$ In 1969 another symposium entitled- The consumption of drugs in Oslo was held, in which it was concluded that an internationally accepted classification system was needed for presenting data on drug consumption. Which resulted in constitution of the WHO European Drug Utilization Research Group (DURG). ${ }^{2,3}$

The main aim of drug utilization research is to facilitate the rational use of drugs in populations. For the individual patient, the rational use of a drug implies the prescription of a documented drug at an optimal dose, together with proper information. ${ }^{4}$

Cardiovascular diseases (CVDs) are the most frequent cause of morbidity and mortality throughout the world. ${ }^{5}$ The common cardiovascular diseases are aneurysm, angina, atherosclerosis, cerebrovascular accident (stroke), cerebrovascular disease, congestive heart failure, coronary artery disease, myocardial infarction (heart attack) and peripheral vascular disease. ${ }^{6}$ The rising cost of healthcare has led to a growing interest in determining the cost and effectiveness of various treatment modalities available to the patient suffering from cardiovascular disease. ${ }^{7}$ 
In the mid $20^{\text {th }}$ century, Coronary care units (CCUs) was a major advance in cardiology practice, as it facilitate the patients with ST elevation myocardial infarction (STEMI) in an area with specialist monitoring. This lead to more specialized and aggressive medical management of STEMI. The development of primary angioplasty (PPCI) programs for STEMI following Roger Boyle's report Mending hearts and Brains' in 2006 has led to a further shift in the role of the CCU. ${ }^{8}$

Outcomes are improved when acute cardiac care is delivered by cardiologists on a cardiology ward. ${ }^{8-10}$ therefore all hospitals should have access to an Acute Cardiac Care Unit with appropriate staffing, if they are admitting patients with medical condition like in the acute phase of their ischemic syndrome, pulmonary edema ,heart failure, cardiac shock, arrhythmia or other hemodynamic disturbance. $^{9}$

In clinical practice irrational prescription of drugs is a common occurrence. Studies from both developed and developing countries describe a pattern that includes polypharmacy, the use of drugs that are not related to diagnosis or unnecessarily expense, the inappropriate use of antibiotics and irrational self - medication with drugs frequently taken in under dose. ${ }^{11}$

To understand the associated difficulties, monitoring of prescriptions and drug utilization studies is required and delivering feedbacks to the physician so as to create awareness for the rational use of drugs.

Therefore this study attempts to evaluate the current utilization patterns of drugs used in CCU in order to facilitate appropriate drug use to reduce the morbidity and mortality of the disease and reduce the unnecessary economic burden on the patient.

\section{METHODS}

The study was carried out at ICCU of cardiology department of K.S. Hegde Charitable Hospital, for a period of six months from January 2016.

Following data was collected:

- The Demographic data

- Diagnosis

- Treatment given

- Duration of stay in the hospital

- Number of drugs prescribed using generic names

Analyzing the above data following indicators were noted:

\section{Prescribing indicators}

- Average number of drugs per patient was calculated (calculated by dividing the total number of different drugs given by the total number of patients).
- Percentage of drugs prescribed by generic names (calculated by dividing the number of drugs used by generic name by the total number of drugs, multiplied by 100$)$.

\section{Patient indicators}

Men to women ratio (determined by dividing the number of men by the Number of women).

Relevant retrospective data as above were also collected from hospital records for period pertaining to six month from $01 / 07 / 2010$ to $31 / 12 / 2010$.

Data from both studies was analyzed using descriptive and appropriate statistical methods to find any significant trends.

\section{RESULTS}

A total of 278 patients who were admitted in CCU of Hospital, 138 patients were admitted in the year 2010 over a period of 6 months, and 140 patient were admitted in the year 2016 over a period of 6 months, based on inclusion and exclusion criteria specified, were studied.

\section{Demographic profile of the patients}

In the year 2010, out of 138 patients 101 were male patients and 37 were female patients. Similarly in 2016, out 140 patients 109 were male and 31 were female patients

\section{Disease profile of the patients}

It was observed that the most common disorder which needed CCU admission in 2010 and 2016 was Acute Coronary Syndrome followed by Heart Failure and Valvular Defect in 2016). Other diseases reported include Arrhythmia, Cardiomyopathies, and Cardiac Shock (Table $1)$.

Table 1: Disease profile of the patients.

\begin{tabular}{|lllll|}
\hline \multirow{2}{*}{ Disease } & $\mathbf{2 0 1 0}$ & & $\mathbf{2 0 1 6}$ \\
\hline ACS and IHD & $\mathbf{N}$ & Percent & N & Percent \\
\hline Heart failure & 317 & $84 \%$ & 116 & $82 \%$ \\
\hline Valvular defect & 20 & $14 \%$ & 54 & $38 \%$ \\
\hline Arrythmia & 16 & $11 \%$ & 23 & $16 \%$ \\
\hline Cardiomyopathies & 2 & $1.4 \%$ & 2 & $15 \%$ \\
\hline Cardiac shock & 5 & $3.6 \%$ & 6 & $4.2 \%$ \\
\hline
\end{tabular}

\section{Polypharmacy}

Out of the total 278 patients included in both year 2010 and 2016, the total number of drugs prescribed was 2242. And in the both retrospective and prospective study polypharmacy has been observed. Number of drugs per 
prescription ranged from $1-16$ and the average number of drugs per prescription was 8.06

In the year 2010, a total of 138 patients admitted in CCU were prescribed 1084 number of drugs. The number of drugs per prescription ranged from 1 - 14 and the average number of drugs per prescription was 7.93.

In the year 2016, a total of 140 patients were admitted in CCU were prescribed a total no of 1158 drugs with the prescription ranged from $1-16$ and the average number of drugs per prescription were 8.27 (Table 2).

\section{Table 2: Frequency of number of drugs prescribed} per patient.

\begin{tabular}{|llll|}
\hline $\begin{array}{l}\text { Number } \\
\text { of drugs } \\
\text { per } \\
\text { patient }\end{array}$ & $\begin{array}{l}\text { Frequency } \\
\text { of patients } \\
\mathbf{2 0 1 0}(\mathbf{n}=\mathbf{1 3 8 )}\end{array}$ & $\begin{array}{l}\text { Frequency } \\
\text { of patients } \\
\mathbf{2 0 1 6}(\mathbf{\%})\end{array}$ & $\begin{array}{l}\text { Total } \\
\text { frequency } \\
\text { of patients } \\
(\mathbf{n}=)\end{array}$ \\
\hline 1 & $0(0 \%)$ & $0(0 \%)$ & $0(0 \%)$ \\
\hline 2 & $1(0.7 \%)$ & $3(2.1 \%)$ & $4(1.4 \%)$ \\
\hline 3 & $5(3.6 \%)$ & $3(2.1 \%)$ & $8(2.8 \%)$ \\
\hline 4 & $5(3.6 \%)$ & $7(5 \%)$ & $12(4.3 \%)$ \\
\hline 5 & $5(3.6 \%)$ & $2(1.4 \%)$ & $7(2.5 \%)$ \\
\hline 6 & $17(12.3 \%)$ & $16(11.4 \%)$ & $33(11.8 \%)$ \\
\hline 7 & $18(13 \%)$ & $20(14.2 \%)$ & $38(13.6 \%)$ \\
\hline 8 & $35(25.3 \%)$ & $21(15 \%)$ & $56(20.1 \%)$ \\
\hline 9 & $25(18.1 \%)$ & $29(20.7 \%)$ & $54(19.4 \%)$ \\
\hline 10 & $5(10.8 \%)$ & $17(12.1 \%)$ & $22(7.9 \%)$ \\
\hline 11 & $6(4.3 \%)$ & $10(7.1 \%)$ & $16(5.7 \%)$ \\
\hline 12 & $3(2.1 \%)$ & $5(3.5 \%)$ & $8(2.8 \%)$ \\
\hline 13 & $1(0.7 \%)$ & $2(1.4 \%)$ & $3(1 \%)$ \\
\hline 14 & $1(0.7 \%)$ & $1(0.7 \%)$ & $2(0.7 \%)$ \\
\hline 15 & $0(0 \%)$ & $2(1.4 \%)$ & $2(0.7 \%)$ \\
\hline 16 & $0(0 \%)$ & $1(0.7 \%)$ & $1(0.3 \%)$ \\
\hline & & & \\
\hline
\end{tabular}

\section{Brand name vs generic name}

Of the 2242 drugs prescribed, 381 (17\%) were written by generic name and $1860(83 \%)$ by brand name. In year 2010, out of total 1084 drugs only 97 (9\%) drugs were prescribed in generic name and $986(91 \%)$ in brand name.

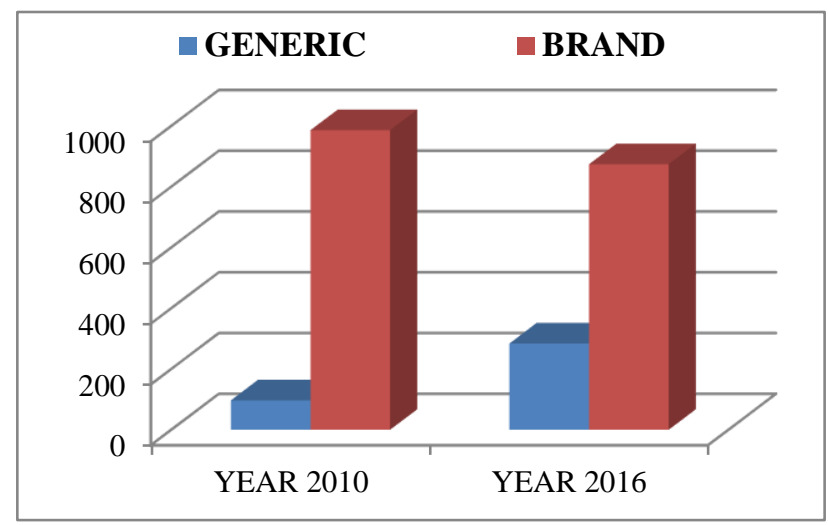

Figure 1: Frequency of generic and brand drug usage.
Similarly, in year 2016, out of total 1158 drugs, $284(24.5 \%)$ drugs were prescribed in generic name and $875(74.5 \%)$ drugs were prescribed in brand name (Figure $1)$.

\section{Co-morbidities associated with CVD}

Most common co-morbid conditions found in patients who increase the risk of CVD were Hypertension (HTN) and Dyslipidemia (DL), followed by Diabetes Mellitus (DM). The incidence of HTN was more compared to DL and DM in patients suffering from CVD.

For 2010, of the total 138 patients, 57 patients (41\%) were Hypertensive, 50 patients $(36 \%)$ were diabetic and 55 patients $(55 \%)$ were found to have Dyslipidemia. For 2016, of the total 140 patients, 61 patients $(43 \%)$ were Hypertensive, 58 patients $(41 \%)$ were diabetic and 59 patients $(42 \%)$ were found to have Dyslipidemia (Figure 2).

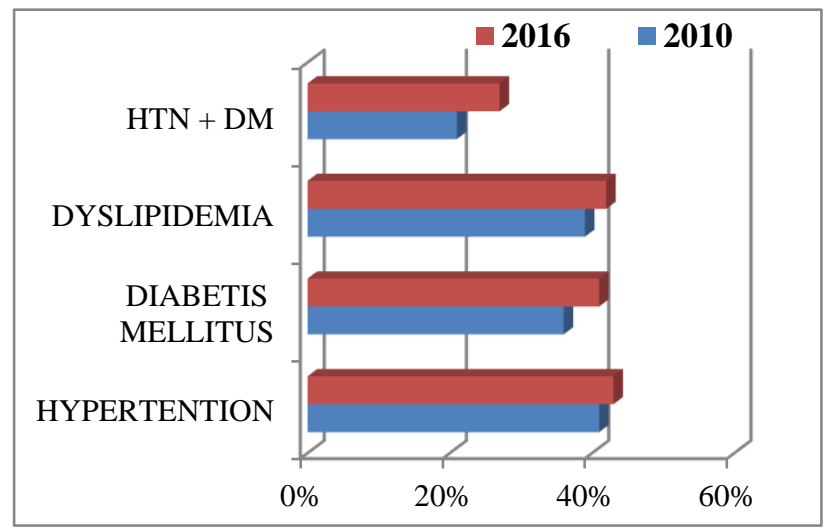

Figure 2: Co-morbidities associated with CVDs.

\section{Duration of hospital stay}

Both retrospective and prospective study showed that most of the patient's duration of hospital stay was less than 7 days i.e. $58 \%$ and $94 \%$ respectively. Moderate number of patient's hospital stay was $32 \%$ in 2010 and $31 \%$ in 2016.

\section{Drug prescribed in IHD}

In the year 2010, out of 117 IHD patients most prescribed drug was nitrates, then followed by aspirin, then clopidogrel, atorvaststin, metoprolol, ramipril, heparin, LMWH, amlodipine, cilostazole, losartan and morphine. In the year 2016, out of 116 IHD patients most prescribed drug was nitrates, then followed by aspirin, then atorvaststin, clopidogrel, heparin, metoprolol, ramipril, amlodipine, LMWH, losartan, morphine, cilostazole (Table 3).

\section{Drugs prescribed in heart failure}

In prospective study among 54 heart failure patients most commonly prescribed drug was nitrates and aspirin, 
followed by clopidogrel, then atorvastatin, torsemide, dobutamine, and furosemide.

In retrospective study among 30 heart failure patients most commonly prescribed drug was nitrates, followed by aspirin and clopidogrel, then atorvastatin, digoxin and torsemide, furosemide and dobutamine (Table 4).

\section{Drugs prescribed valvular heart disease}

In conservative management in 2010, penicillin was prescribed to 6 patients $(30 \%)$ and warfarin to 10 patients $(50 \%)$. Similarly in 2016, penicillin prescribed to 4 patients $(17 \%)$ and warfarin to 11 patients $(47 \%)$.

Table 3: Percentage of drugs prescribed in IHD during 2010 and 2016.

\begin{tabular}{|lllll|}
\hline Drugs used in IHD & $\begin{array}{l}\text { Year } \\
\text { Frequency of } \\
\text { prescription }\end{array}$ & $\mathbf{2 0 1 0}$ & $\begin{array}{l}\text { Year } \\
\text { Prequency of } \\
\text { prescription }\end{array}$ & Percentage of patient \\
\hline Aspirin & 113 & $97 \%$ & 112 & $95 \%$ \\
\hline Atorvastatin & 98 & $84 \%$ & 110 & $94 \%$ \\
\hline Clopidogrel & 107 & $92 \%$ & 106 & $90 \%$ \\
\hline Nitrates & 116 & $100 \%$ & 117 & $100 \%$ \\
\hline Metoprolol & 84 & $72 \%$ & 59 & $50 \%$ \\
\hline Amlodipine & 19 & $16 \%$ & 19 & $16 \%$ \\
\hline Ramipril & 59 & $50 \%$ & 30 & $25 \%$ \\
\hline Morphine & 6 & $5 \%$ & 7 & $7 \%$ \\
\hline Heparin & 56 & $48 \%$ & 80 & $68 \%$ \\
\hline Losartan & 8 & $6 \%$ & 9 & $7 \%$ \\
\hline Cilostazole & 11 & $9 \%$ & 4 & $3 \%$ \\
\hline Lmwh & 19 & $16 \%$ & 18 & $15 \%$ \\
\hline
\end{tabular}

Table 4: Percentage of drug prescribed in HF during 2010 and 2016.

\begin{tabular}{|lllll|}
\hline HF Drugs & $\begin{array}{l}\text { Year } \\
\text { Frequency of } \\
\text { prescription }\end{array}$ & Percentage of patient & $\begin{array}{l}\text { Year } \\
\text { Frequency of } \\
\text { prescription }\end{array}$ & Percentage of patient \\
\hline Digoxin & 5 & $16 \%$ & 0 & $0 \%$ \\
\hline Torsemide & 5 & $16 \%$ & 20 & $37 \%$ \\
\hline Furosemide & 3 & $10 \%$ & 5 & $9 \%$ \\
\hline Dobutamine & 2 & $6 \%$ & 11 & $20 \%$ \\
\hline Clopidogrel & 26 & $86 \%$ & 53 & $98 \%$ \\
\hline Asprin & 26 & $86 \%$ & 54 & $100 \%$ \\
\hline Nitrates & 30 & $100 \%$ & 54 & $100 \%$ \\
\hline Atorvastatin & 24 & $80 \%$ & 52 & $96 \%$ \\
\hline
\end{tabular}

\section{Drugs prescribed in arrhythmia}

In 2010 study, among 16 arrhythmia patients most commonly prescribed drug was digoxin (6 patients $37 \%$ ), followed by warfarin ( 5 patients $31 \%$ ), then virapamil and diltiazem (3 patients 18\%), amiodarone and metoprolol (3 patients 18\%). In 2016 study among 22 arrhythmia patients most commonly prescribed drug was diltiazem, metoprolol and atropine (5 patients $22 \%$ ), followed by amiodarone (3 patients 13\%), and warfarin (1 patients $4 \%)$.

\section{Drug prescribed in cardiomyopathy}

In retrospective study of cardiomyopathy it was observed that furosemide and ramipil was most used drugs (100\%) followed by warfarin and nitrate $(50 \%)$. In prospective study of cardiomyopathy it is observed that most used drug is furosemide and nitrate $(100 \%)$ followed by warfarin, spironolactone and ramipil $(50 \%)$.

\section{DISCUSSION}

Analysis of drugs utilization forms a major tool for assessing the quality of patient care accorded in a healthcare system. Maximum benefit can be obtained with appropriate selection of drugs and reduces the side effects.

A total number of 278 cases of cardiovascular diseases admitted in CCU were evaluated in this study; out of which 138 retrospective cases were studied over a period of six 
months in the year 2010 and 140 prospective cases were studied over a period of six months in the year 2016.

Our study showed female patients admitted in CCU with cardiovascular disease are significantly less than male in both the years. ${ }^{12} \mathrm{With}$ a male: female ratio of 2.7: 1 in 2010 and 3.5:1 in 2016. Similar result was seen in studies. ${ }^{13,14}$

In our study it was observed that most common disease which required CCU admission in both 2010 and 2016 was acute coronary syndrome and Ischemic heart disease, with a high percentage of $84 \%$ and $82 \%$ respectively. But there were not much differences between both years. Next highest admission was for heart failure with a percentage of $21 \%$ and $38 \%$ in 2010 and 2016 respectively. which were in accordance with. ${ }^{13}$ But in our study number of patients with heart failure increased from $21 \%$ in 2010 to $38 \%$ in 2016, followed by RHD with defect and cardiomyopathy.

Both in retrospective and prospective study polypharmacy were observed. Polypharmacy may be justified as this was a CCU setup where the majority of patients were hospitalized with multiple co morbidities. This result was similar to the finding by George et al. ${ }^{15}$ Comparing 2010 with 2016 shows average number of drugs per prescription is increased in prospective study.

The duration of hospital stay in prospective study is reduced compared to retrospective study. The interplay of polypharmacy and multiple co morbidities are proven risk factors for ADRs, which results in increase the duration of hospital stay. ${ }^{16}$

In our study prescription of drugs in generic name significantly increased from retrospective study (9\%) to prospective study $(24.5 \%)$. And use of brand name in prescription in reduced from $91 \%$ to $74 \%$ respectively. Which shows higher prescription of generic names compared to other study. ${ }^{17,18}$

Most common co-morbidities associated seen in CCU admitted patients were hypertension that we found in our study. In our study while comparing the Co-morbidities associated with CVD in both retrospective and prospective study, found that all co-morbidity association increased in prospective study. In India prevalence of hypertension, for the last three decades, has increased by about 30 times among urban and 10 times among rural residents. Diabetes mellitus and hypertension are major and modifiable risk factors which when controlled can significantly reduce CVD morbidity and mortality. ${ }^{19}$

In a study most commonly prescribed medication in CCU was Antiplatelet drugs, followed by hypolipidemic drugs. Among antiplatelet drugs, aspirin, clopidogrel, and their combination were prescribed. ${ }^{13}$ In another study by George et al. clopidogrel was used in almost all IHD patients. Similarly in our study after nitrates, antiplatelet like aspirin and clopidogrel was used more commonly followed by atorvaststin, beta blockers, ACE inhibitors, anticoagulant like heparin and LMWH in both retrospective and prospective study. But use of anticoagulant is significantly increased from $48 \%$ in 2010 to $68 \%$ in 2016 . It is also seen that almost all patients received both Aspirin and Clopidogrel in both years. This is in line with updated 2007 recommendation of dual antiplatelet therapy in ACS, which has proven to confer a $20 \%$ reduction in cardiovascular events in both low and high risk patients. ${ }^{20,21}$

Comparison between both years of prescription for Heart Failure shows that use of digoxin has come down from $16 \%$ in the year 2010 to $0 \%$ in the year 2016. Whereas use of inotropes like dobutamine is increased from 6\% in 2010 to $20 \%$ in 2016.

In medical management of Valvular Heart Diseases patients in our study received penicillin and warfarin in both years. But use of penicillin was reduced in 2016 . Similarly we observed in medical management of Arrhythmia use of digoxin reduced from 37\% in 2010 to $0 \%$ in 2016. Similarly use of verapamil also reduced from $18 \%$ to $0 \%$ respectively. Cardiomyopathy was mostly managed with Diuretics, ACEIs, and Nitrates in both retrospective and prospective study.

Reducing the number of drugs per prescription would result in an efficient prescribing pattern. Usage of generic drugs in the prescription will reduce the economic burden of the patient.

In our study, on analyzing the drug prescription data it was observed that there was no statistically significant change in drug utilization between the two years. The study of drug utilization is a component of a medical audit that does monitoring and evaluation of the prescription and suggests necessary reformations to achieve rational and costeffective medical care. The results of this study will help prescribers enhance patient management by rationalizing prescribing practices.

\section{CONCLUSION}

It has been found that the drugs used in CCU of Justice K. S. Hegde Charitable Hospital, is in conformity with the rational use of drugs which is based on clinical knowledge, expertise and the guidelines available.

\section{ACKNOWLEDGEMENTS}

The authors express thanks to the Department of Pharmacology and Department of Cardiology KSHEMA and the participants for their contribution to the study.

Funding: No funding sources

Conflict of interest: None declared

Ethical approval: The study was approved by the Institutional Ethics Committee 


\section{REFERENCES}

1. Wiholm BE, Westerholm B. Drug utilization and morbidity statistics for the evaluation of drug safety in Sweden. Acta Med Scand Suppl. 1984;683:107-17.

2. Dukes MN. Drug utilization studies. Methods and uses. Introduction. WHO Reg Publ Eur Ser. 1993;45:1-4.

3. Introduction to Drug Utilization Research: Preface: Drug utilization research - the early work [Internet]. [cited 2017 Oct 12]. Available at: http://apps.who.int/medicinedocs/en/d/Js4876e/1.htm l\#Js4876e. 1

4. Introduction to Drug Utilization Research: Chapter 1: What is drug utilization research and why is it needed?: 1.2 Why drug utilization research? [Internet]. [cited 2017 Oct 12]. Available at: http://apps.who.int/medicinedocs/en/d/Js4876e/2.2.ht ml\#Js4876e.2.2

5. Pendhari SR, Chaudhari DR, Burute SR, Bite BM. A study on the drug utilization trends in the cardiovascular emergencies in a tertiary care hospital. J Clin Diagn Res JCDR. 2013 Apr;7(4):666-70.

6. Evaluation of the Rationality of Fixed Dose Combinations of Cardiovascular drugs in a Multispecialty Tertiary care hospital in Coimbatore, Tamilnadu, India [Internet]. [cited 2017 Oct 12]. Available at https://www.researchgate.net/publication/235950292 _Evaluation_of_the_Rationality_of_Fixed_Dose_Co mbinations_of_Cardiovascular_drugs_in_a_Multispe cialty_Tertiary_care_hospital_in_Coimbatore_Tamil nadu_India

7. Sokol MC, Mcguigan KA, Verbrugge RR, Epstein RS. Impact of medication adherence on hospitalization risk and healthcare cost. Med Care. 43(6):521-30.

8. BCS_Report_on_Coronary_Care_Units.pdf [Internet]. [cited 2017 Oct 13]. Available at: http://www.bcs.com/documents/BCS_Report_on_Co ronary_Care_Units.pdf

9. Herrett E, Smeeth L, Walker L, Weston C. The Myocardial Ischaemia National Audit Project (MINAP). Heart. 2010 Aug;96(16):1264-7.

10. Birkhead JS, Weston C, Lowe D. Impact of specialty of admitting physician and type of hospital on care and outcome for myocardial infarction in England and Wales during 2004-5: observational study. BMJ. 2006 Jun 3;332(7553):1306-11.

11. brjclinpharm00013-0005.pdf [Internet]. [cited 2017 Oct 12]. Available at: https://www.ncbi.nlm.nih.gov/pmc/articles/PMC1364 974/pdf/brjclinpharm00013-0005.pdf

12. Patel MK, Barvaliya MJ, Patel TK, Tripathi C. Drug utilization pattern in critical care unit in a tertiary care teaching hospital in India. Int $\mathbf{J}$ Crit Illn Inj Sci. 2013;3(4):250-5.
13. Nagabushan H, Roopadevi HS, Prakash GM, Pankaja R. A prospective study of drug utilization pattern in cardiac intensive care unit at a tertiary care teaching hospital. Int J Basic Clin Pharmacol. 2017 Jan 18;4(3):579-83.

14. Al-Junid SM, Ezat WPS, Surianti S. Prescribing patterns and drug cost among cardiovascular patients in Hospital Universiti Kebangsaan Malaysia. Med J Malaysia. 2007 Mar;62(1):59-65.

15. George J, Devi P, Kamath DY, Anthony N, Kunnoor NS, Sanil SS. Patterns and determinants of cardiovascular drug utilization in coronary care unit patients of a tertiary care hospital. J Cardiovasc Dis Res. 2013 Dec;4(4):214-21.

16. Classen DC, Pestotnik SL, Evans RS, Lloyd JF, Burke JP. Adverse Drug Events in Hospitalized Patients: Excess Length of Stay, Extra Costs, and Attributable Mortality. JAMA. 1997 Jan 22;277(4):301-6.

17. Shankar PR, Upadhyay DK, Subish P, Bhandari RB, Das B. Drug utilisation among older inpatients in a teaching hospital in Western Nepal. Singapore Med J. 2010 Jan;51(1):28-34.

18. Hedamba R, Doshi C, Darji NH, Patel B, Kumari V, Trivedi HR. Drug utilization pattern of antimicrobial drugs in intensive care unit of a tertiary care hospital attached with a medical college. Int $\mathrm{J}$ Basic Clin Pharmacol. 2016 Dec 24;5(1):169-72.

19. Rodgers A, Lawes C, MacMahon S. Reducing the global burden of blood pressure-related cardiovascular disease. J Hypertens Suppl Off J Int Soc Hypertens. 2000 May;18(1):S3-6.

20. Investigators $\mathrm{TC}$ in UA to PRET. Effects of Clopidogrel in Addition to Aspirin in Patients with Acute Coronary Syndromes without ST-Segment Elevation. N Engl J Med. 2001 Aug 16;345(7):494502.

21. King SB, Smith SC, Hirshfeld JW, Jacobs AK, Morrison DA, Williams DO, et al. Focused Update of the ACC/AHA/SCAI 2005 Guideline Update for Percutaneous Coronary Intervention: A Report of the American College of Cardiology/American Heart Association Task Force on Practice Guidelines: 2007 Writing Group to Review New Evidence and Update the ACC/AHA/SCAI 2005 Guideline Update for Percutaneous Coronary Intervention, Writing on Behalf of the 2005 Writing Committee. Circulation. 2008 Jan 15;117(2):261-95.

Cite this article as: Sharma SN, Holla R, Subramanyam K, Srinivas M. Periodic evaluation of drug utilization in intensive coronary care unit patients in a tertiary care hospital. Int $\mathbf{J}$ Basic Clin Pharmacol 2018;7:292-7. 